\title{
Special issue on commercial design optimization software: an introductory note
}

\author{
Panos Y. Papalambros (Guest Editor)
}

Thinking of this special issue I recall a discussion I had with Professor Jim Siddall from McMaster University at a research meeting circa 1982. At the time, I had been working on design optimization for just a few years while Jim had published several books on the subject and was one of the senior respected figures in the field. I was lamenting the fact that with all the work that had been done on design optimization the folks in industry were hardly using the techniques we advocated and they seemed to be downright barbarians in their approach to design. Jim kindly responded to the effect that I should hold my horses and that when we "optimizers" truly had the right stuff the folks in industry would surely use it.

Twenty years later I have come to understand the true meaning of Jim Siddall's comment. Having worked with several colleagues in industry across the world and having followed their work quite closely I came to a couple of conclusions: The complexity of the optimal design problems that our industry colleagues address successfully far exceeds what many of us academics suspect or even dare undertake. Furthermore, the true heroes of the indisputable growth of design optimization use in industry (or the academy for that matter) are the "commercial" software vendors-the companies and the people who have tried to put together software packages that are robust, friendly and accessible to users that may lack the sophistication or the time to use the immediate products of the academic endeavor. To be fair, these commercial software entities would not have been possible without the intellectual fruits of the academic research. The point however is not to minimize the latter's importance; rather, it is to recognize that we should applaud all such "commercial" efforts, filter the hype of the marketplace, and support their collective use by students and colleagues in academia and industry alike. For example, thanks to the Excel Solver I have been able to do the

September 2001

Panos Y. Papalambros (Guest Editor)

College of Engineering, University of Michigan, 2250 G.G. Brown Building, Ann Arbor, MI 48109-2125, USA

e-mail: pyp@umich.edu unimaginable (to me anyway): have second-year college sophomores use design optimization intelligently in their project work.

Thus, two years ago with encouragement from Vassili Toropov I undertook the project of establishing some sort of state of the art in commercial design optimization software by inviting the key players to make a bona fide journal article contribution into a special issue collection. The requirements put forth in the invitations were that (i) each article would not be a covert commercial marketing pitch, (ii) the capabilities and limitations of the software would be reasonably outlined, (iii) some specific examples of applications would be offered, and (iv) that the software in question would be available on the open market along with support and maintenance contracts (to exclude the extensive semi- commercial activities of many academics). Initially my intention was to concentrate only on non-structural software because of the extensive inclusion of optimizers in recent versions of FEM packages. Subsequently, I included structural optimization software as long as they were not a small part of a larger FEM package. The initial collection of papers reflects writings that took place about a year ago and I think that on the whole we met the requirements we set forth. The state of the art in algorithms and computational environments is evolving at a fast pace, yet I believe that the special issue herein will maintain its archival value as I am not aware of any other collection of its kind. The collection is reasonably complete, even though more contributions could have been included. (For example, I was unable to obtain a contribution from the developers of the Excel Solver but if they used the time to continue improving their product I could not complain.)

I want to thank Vassili Toropov and George Rozvany for their support throughout this effort, as well as the many reviewers who kindly offered their advice and help in improving the manuscripts. One can say that all those individuals working in the field of design optimization are making a living out of it but this is painfully true for the authors of the articles in this special issue. And so I would like to express to them my gratitude and my respect.

Panos Y. Papalambros, Ann Arbor, September 2001 


\section{Editor's Notes}

Papers appearing in this Special Issue were originally submitted to and accepted by the discontinued journal "Design Optimization" which later merged with "Structural and Multidisciplinary Optimization". The date of receipt (December 30, 2000) of the papers refers to the date when they arrived in the Editorial Office of the latter. The manuscripts were received by "Design Optimization" already early in 2000. The Editor wishes to express his thanks to Panos Papalambros and Vassili Toropov for their excellent efforts.

Apart from the review article by Thomas et al., papers on commercial software appear in alphabetical order of the first authors' names.

Due to publication timing, an article describing the GENESIS optimization software produced by Vanderplaats and his Associates has not been included in this special issue. We hope to see it appear in a future regular issue of the Journal. 